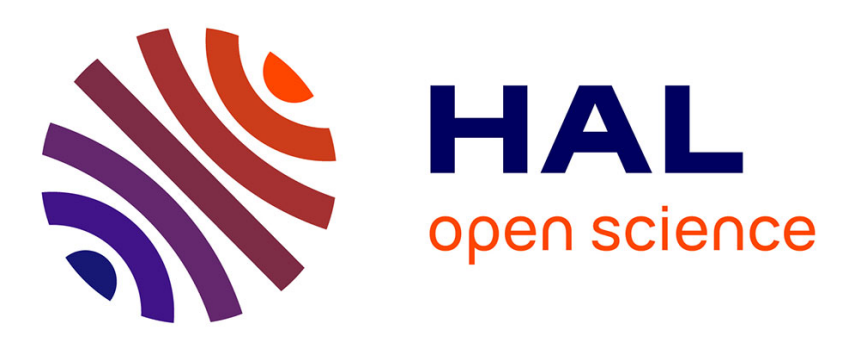

\title{
Physical modelling of soil-structure interaction in the subsidence area
}

\author{
Luyen Nghiem, Fabrice Emeriault, Marwan Al Heib
}

\section{To cite this version:}

Luyen Nghiem, Fabrice Emeriault, Marwan Al Heib. Physical modelling of soil-structure interaction in the subsidence area. 8. International Symposium on Geotechnical Aspects of Underground Construction in Soft Ground (IS-Seoul), Aug 2014, Seoul, South Korea. pp.185-190. ineris-01855641

\section{HAL Id: ineris-01855641 \\ https://hal-ineris.archives-ouvertes.fr/ineris-01855641}

Submitted on 6 Sep 2018

HAL is a multi-disciplinary open access archive for the deposit and dissemination of scientific research documents, whether they are published or not. The documents may come from teaching and research institutions in France or abroad, or from public or private research centers.
L'archive ouverte pluridisciplinaire HAL, est destinée au dépôt et à la diffusion de documents scientifiques de niveau recherche, publiés ou non, émanant des établissements d'enseignement et de recherche français ou étrangers, des laboratoires publics ou privés. 


\title{
Physical modelling of soil-structure interaction in the subsidence area
}

\author{
H.L. Nghiem \& F. Emeriault \\ University of Grenoble Alpes, 3SR, Grenoble, France
}

M. Al Heib
Ineris-Parc Technologique Alata, Verneuil en Halatte, France

\begin{abstract}
Failures of underground structures can affect the existing building on the ground surface. Investigation of soil-structure interactions is one of the most effective means of predicting the effect of failures on future structures and assessing damage on structures already existing in a subsidence area. The paper presents experimental results of the phenomena using a large scale physical model representing a masonry structure subject to subsidence settlement, using $1 / 40$ scale factor on geometry and under the normal gravity. Homogenous sand is used for the analogue soil and the analogue masonry structure is built from small wooden pieces. Comparison of different positions of the structure on the surface is considered. Transfer ratios of displacements, slope, and deflexion are adopted to study the structure behaviour compared to the ground. Besides, the damage is evaluated with different criteria and completed by the consideration of the crack positions on the structure provided by Digital Image Correlation (DIC) technique.
\end{abstract}

Keywords: soil-structure interaction, physical modelling, damage assessment, digital correlation image

\section{INTRODUCTION}

The ground movement associated with the collapse of the underground voids such as mines, tunnels could affect the building on the surface. Understanding the soil-structure interaction is a great objective for engineering applications in particular for the assessment of structure damages. Following the numerical approaches of Potts and Addenbrooke, 1997 and Deck et al., 2003, the interaction can be characterized by the relative stiffness between the soil and the structure. The use of transfer ratios of deflexion has been suggested by Potts and Addenbrooke, 1997, whereas Deck et al., 2003 compared the difference of curvature and horizontal strain between the structure and the ground. Nevertheless, the main difficulty of the numerical models is the estimation of the ground stiffness.

The assessment of damage in a structure induced by the soil-structure interaction can be based on different criteria such as tensile limit strain (Boscardin and Cording, 1989), limit slope (see Loganatban, 2011), and crack width (Burland, 1997). Indicators based on these criteria allow quantifying damage but remain insufficient to determine the damage location on the structure. Therefore, the damage assessment could be no more accurate.

Recent physical models such as Laefer et al., 2011, and Giardina et al., 2012 have been developed in order to improve the knowledge of the relation between the damage in the structure and the soil-structure interaction. Nevertheless, these investigations are limited with only one position of the structure with respect to the centre of the settlement trough.

In this study, soil-structure interaction is quantified (with a particular attention to the effect of the different position of the structure in a subsidence area and the method used for damage assessment) based on results of physical modelling. Herein, the proposed physical model is a small-scale mock-up of a typical individual house made of masonry mostly present in the subsidence areas of the East and North of France. The model uses homogenous sand for the analogue soil and the analogue structure is built from small wooden pieces with no consideration of mortar at the joints, i.e., the blocks have no cohesion and contact each other by the friction. The ground settlement is applied using a mechanical-electrical jack. The displacement fields of the soil and the structure are captured by high-speed cameras. The recorded images are then analysed with a Digital Image Correlation (DIC) software. The soil-structure interaction is characterized by transfer ratios of displacements, slope, and deflexion between the greenfield situation and the case with the structure. The damage assessment is discussed with a comparison of different methods, taking into account the positions of cracks on the structure. 


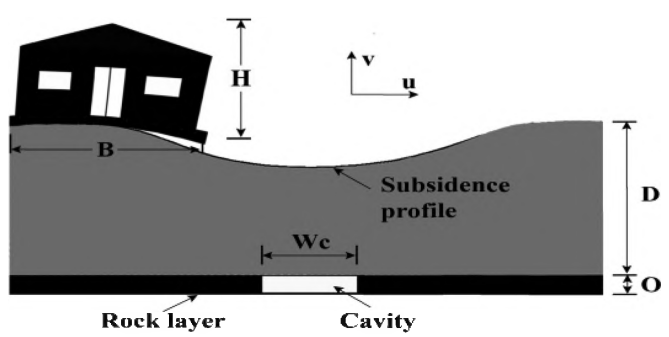

(a)

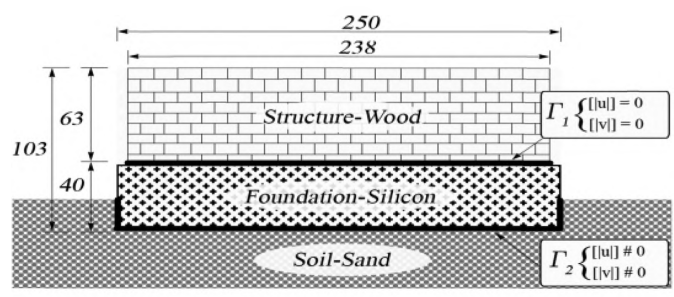

(b)

Figure 1. Description of problem. a) Buliding on surface. b) Scheme of the INERIS physical model (1/40 scale factor)-distances in $\mathrm{mm}$. $\mathrm{D}$ is the depth of the cavity, $\mathrm{O}$ is the thinkness of the layer, and Wc is the width of the cavity.

\section{PHYSICAL MODELLING FOR SOIL-FOUNDATION-STRUCTURE INTERACTION}

\subsection{Physical model concept}

The description of problem and the corresponding physical model are shown in Figure 1: D is the depth of the void (cavity), $\mathrm{O}$ is the thickness of the layer, and $\mathrm{Wc}$ is the width of the cavity. The design and the choice of materials is extensively discussed in recent works (Al Heib et al., 2013). Briefly, the platform (tank) has dimensions of $3 \times 2 \times 1 \mathrm{~m}^{3}$ and is filled up with a homogeneous sand layer. The structure model is equivalent to the prototype of an ordinary house found in hazard zones, with typical dimensions $10 \times 10 \mathrm{~m}^{2}$. The similitude laws are generally difficult to fulfill because of the choice of materials. In the present model, the similitude is given with restraint on the geometry (length, area, volume), the material behaviour is the second priority. The use of $1 / 40$ scale factor on geometry provides the dimensions $0.25 \times 0.25 \mathrm{~m}^{2}$ for the model. For the analogue of the material behaviour, the bending and axial stiffness of the structure are chosen because they are the most important for the soil-structure interaction investigation. Here, the volume of the foundation model is 1.9 litre, the density is $0.9 \mathrm{kN} / \mathrm{m}^{3}$, the Young's modulus is $5 \mathrm{MPa}$, the bending stiffness is $3.3 \mathrm{~N} \cdot \mathrm{m}^{2}$ (according to $1 / 40^{5}$ scale factor), and the axial stiffness is $0.036 \mathrm{MN}$ (according to $1 / 40^{3}$ scale factor). The analogue soil is the Fontainebleau sand (essentially silica with $\mathrm{SiO}_{2}>98 \%$ ) and an initial relative density of $44 \%$ (medium dense conditions).

The initial condition in Figure $1 \mathrm{~b}$ presents two particular interfaces: wood blocks-silicon $\Gamma_{1}$ and silicon-sand $\Gamma_{2}$, the silicone corresponding to the raft foundation in contact with the soil (sand layer). The first interface $\Gamma_{1}$ has a perfect bounding, which is helpful for an easy implantation of the model into the platform. The second interface $\Gamma_{2}$ is a simple frictional contact of the silicon foundation with sand maintained by the normal force applied by the weight of the structure.

The sand is manually fulfilled in the tank by layers of $15 \mathrm{~cm}$ thickness. Each layer is compacted by a heavy hammer to ensure the density for all points on surface. The task is repeated until the required depth of the soil layer $\mathrm{D}$, in this case, $\mathrm{D}=30 \mathrm{~cm}$. Finally, the horizontal level of the sand surface is obtained by using a wide rule (Al Heib et al., 2013).

\subsection{Test procedure}

The test procedure can be summarized in three main steps: (i) the platform is first filled with a homogeneous layer of Fontainebleau sand up to $30 \mathrm{~cm}$ (equal to $12 \mathrm{~m}$ depth) and then the model is set up inside, (ii) The ground movement is reproduced using the mechanicalelectrical jack at the bottom of the tank applying a localized vertical displacement with a low speed $(0.15 \mathrm{~mm} / \mathrm{s})$, and (iii) The Digital Image Correlation (DIC) technique is used to monitor the displacement fields of both the structure and the ground surface.

In this work, the commercial software VIC-3D from Limess $\mathrm{GmbH}$ was chosen, which provides full-field, 3-Dimensional measurements of shape, displacement and strain. Four high-resolution cameras have been used with a maximum frequency of 8 images/second. The two first cameras are dedicated to recording images of masonry façade and the other two are set up with the purpose of investigating the sand movements at the ground surface. A good calibration allows obtaining accurate measurements with an error of $1 / 100$ of a pixel. However, the recording of images requires a huge volume of data storage. For example, a single test needs nearly 8 GB of raw data for each minute in case of the use of the maximum frequency of capture.

\section{EXPERIMENTAL RESULTS}

\subsection{Greenfield}

The subsidence profile without any building on the surface is characterized by the amplitude of subsidence and the limit of the influence zone. With an applied vertical displacement of the jack ranging 0 to $30 \mathrm{~mm}$, the maximal vertical displacement at the ground surface (subsidence) $\mathrm{W}_{\max }$ attains $24 \mathrm{~mm}$, corresponding to a maximum of the influence angle of $45^{\circ}$. The subsidence profile can be fitted with Peck's approach (see Al Heib et al., 2013), i.e. the vertical displacement is estimated by an exponential function: $\mathrm{W}(\mathrm{x})=\mathrm{W}_{\max } \times \exp \left(-\mathrm{x}^{2} / 2 \mathrm{i}^{2}\right)$, where $\mathrm{W}(\mathrm{x})$ is the vertical displacement at a distance $\mathrm{x}$ from the 

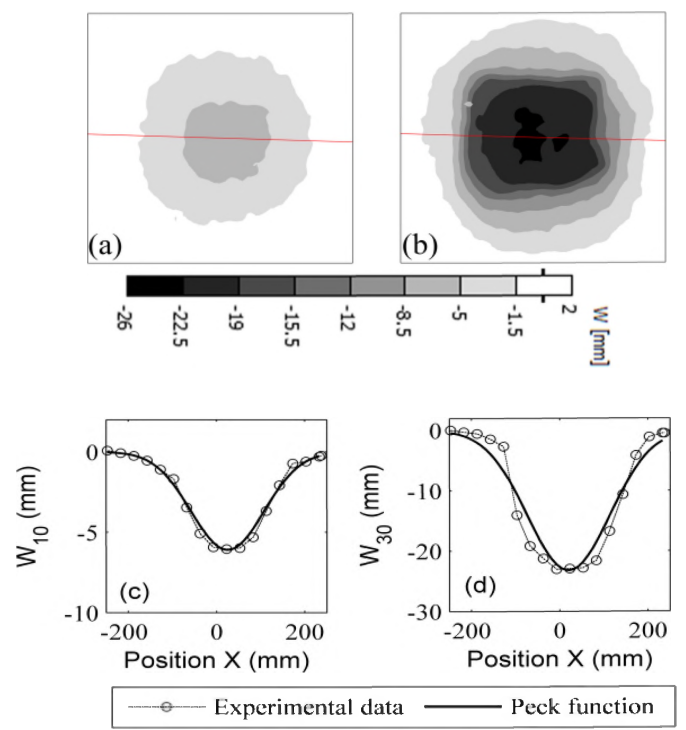

Figure 2. Greenfield subsidence profiles corresponding to the jack displacement of (a, c) $10 \mathrm{~mm}$, and (b, d) $30 \mathrm{~mm}$. W is the vertical displacement of the ground.

centre of the settlement trough, $\mathrm{W}_{\max }$ is the maximum vertical displacement, and $i$ is the distance from the trough centre to the inflexion point. The latter is determined experimentally $i=110 \pm 15 \mathrm{~mm}$ during the tests. Nevertheless, the Peck' approach is applicable when the displacement of jack in smaller than $10 \mathrm{~mm}$, in which case the curve presents only one maximum value at the centre (Figs. 2a, c). Beyond this threshold, the subsidence appears as a zone of constant maximum settlement around the centre of the curve (Figs. 2b, d). This phenomena also exists in many cases in the reality as mentioned by Al Heib, 2003. According to this study, the theoretical functions, e.g. Peck's formula, are applicable when the trough width is smaller than its critical value $\mathrm{L}_{\mathrm{cr}}$, equal to the thickness of the ground layer D.

\subsection{Case of presence of the structure on surface}

Figure 3 represents three critical zones on the settlement trough: sagging zone $\left(\mathrm{P}_{1}\right)$, hogging zone $\left(\mathrm{P}_{2}\right)$, and mixed zone $\left(\mathrm{P}_{3}\right)$, i.e. hogging in $\mathrm{x}$ direction and sagging in y direction. Geometrically, $\mathrm{P}_{1}$ does no present any eccentricity between the structure model and the jack, $\mathrm{P}_{2}$ has an eccentricity in both of $\mathrm{x}$ and $\mathrm{y}$ directions, whereas $\mathrm{P}_{3}$ has an eccentricity only in the $\mathrm{x}$ direction and is centered in $\mathrm{y}$ direction. The facade observed by the cameras is along the $\mathrm{x}$ direction. Figure 3 also captured the final states of the structures in the different positions. In particular, the walls of the structure in position $\mathrm{P}_{3}$ is collapsed when the displacement of jack reaches $20 \mathrm{~mm}$. Unfortunately, the soil displacements for $\mathrm{P}_{1}$ and $\mathrm{P}_{3}$ are not exploitable

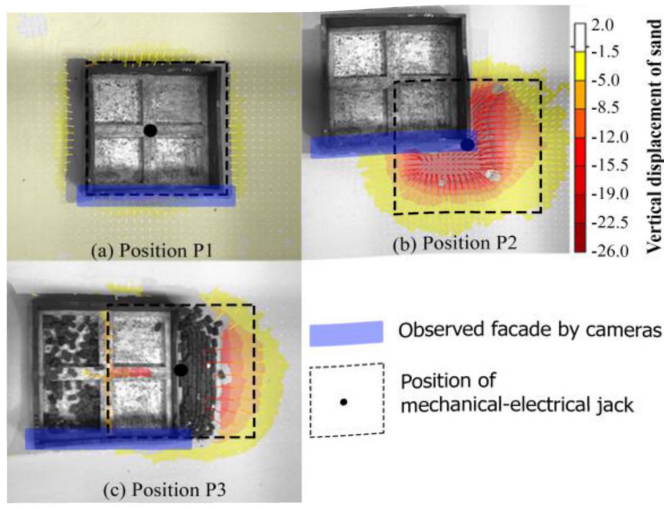

Figure 3. Critical positions of the structure in (a) sagging zone, (b) hogging zone, and (c) mixed zone (tension in the $\mathrm{x}$ direction and compression in the $\mathrm{y}$ direction).

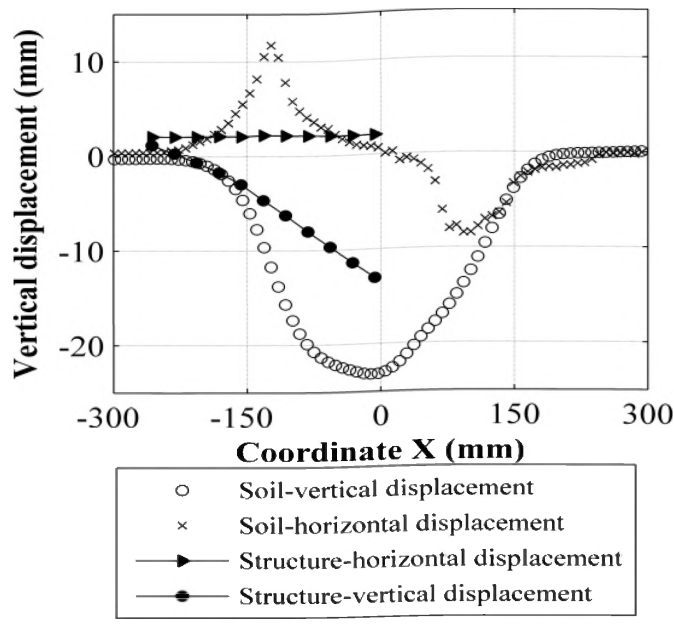

Figure 4. Displacements of soil and structure at the final state (jack displacement is $30 \mathrm{~mm}$ ) for the structure in the hogging zone (position $\mathrm{P}_{2}$ ). $\mathrm{x}=0$ is the centre of the through

due to the loss of correlation between images. In fact, the structure area hides a significant portion of the soil, consequently the DIC cannot analyse this. However, the results obtained for $\mathrm{P}_{2}$ are always interesting as represented in Figure 4.

In the case of position $\mathrm{P}_{2}$ (Fig. 4), the ground displacements are dissymmetric (compared to the Greenfield case) with the soil in the left part (mainly concerned by the structure) having more significant values than the "Greenfield" part on the right. This can be explained by the fact that the weight of the structure added a complementary load on the ground inducing more significant movements of soil. This observation is also confirmed by Caudron, 2007, and Hor, 2012.

Concerning the structure displacements for position $\mathrm{P}_{2}$, there are three different areas: (i) uplift area nearby the left extremity of the structure, i.e. from $\mathrm{x}=-250$ to $-210 \mathrm{~mm}$ (Fig. 4), (ii) soil-foundation contact, from $\mathrm{x}=-210$ to $-150 \mathrm{~mm}$, and (iii) non-contact 

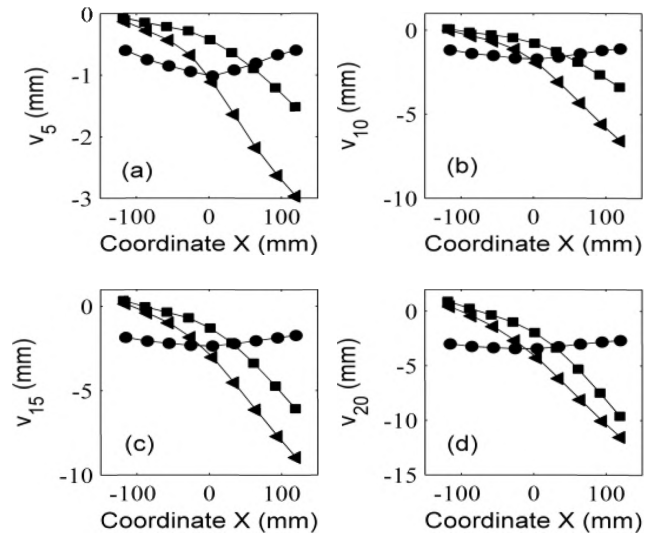

- Position $1 \longrightarrow$ Position $2 \longrightarrow$ Position 3

Figure 5. Displacements of the foundation corresponding to the jack displacement of (a) $5 \mathrm{~mm}$, (b) $10 \mathrm{~mm}$, (c) $15 \mathrm{~mm}$, and (d) $20 \mathrm{~mm} . \mathrm{x}=0$ is the centre of the foundation. " $\mathrm{v}$ " is the vertical displacement of the foundation.

area from $\mathrm{x}=-150$ to $0 \mathrm{~mm}$. The maximal value of the vertical displacement is $2 \mathrm{~mm}$ in the uplift area and $13 \mathrm{~mm}$ in the non-contact area. Besides, the horizontal displacement of the structure is mostly constant, indicating that the structure mainly behaves as a rigid body.

Figure 5 compares the vertical displacements of the structure (measured by DIC) in the three positions related to a jack displacement of $5 \mathrm{~mm}$ (Fig. 5a), $10 \mathrm{~mm}$ (Fig. 5b), $15 \mathrm{~mm}$ (Fig. 5c), and $20 \mathrm{~mm}$ (Fig. 5d). The comparison for $30 \mathrm{~mm}$ cannot be done due to the collapse of the structure model in $\mathrm{P}_{3}$ (the zone of interest of the DIC on the silicone foundation is disturbed and the information is lost).

In this figure, the vertical displacements of $\mathrm{P}_{1}$ are different from $\mathrm{P}_{2}$ and $\mathrm{P}_{3}$ : the settlement of foundation of $\mathrm{P}_{1}$ is almost uniform along its length whereas the behaviours of $P_{2}$ and $P_{3}$ resemble that of a cantilever beam. Nonetheless, there are small differences of displacement for these two positions: the vertical displacements of $\mathrm{P}_{2}$ are always more significant than that of $\mathrm{P}_{3}$. This can be explained by the fact that these two positions are in extension in the $\mathrm{x}$ direction, but that the structure in $\mathrm{P}_{3}$ is in compression in the $\mathrm{y}$ direction while there is no eccentricity for $P_{1}$. Therefore, the compression in y direction restraints the settlement of the silicon foundation in the $\mathrm{x}$ direction (direction of the facade monitored by cameras).

\subsection{Transfer ratios from the ground onto the structure}

This section discusses the soil-structure interaction and answers to the question of structure stiffness compared to the soil stiffness. To do this, we establish different ratios between the behaviour of the structure and the behaviour in greenfield: $\tau=$ Structure/Greenfield. In particular, when $\tau=1$, the structure and the
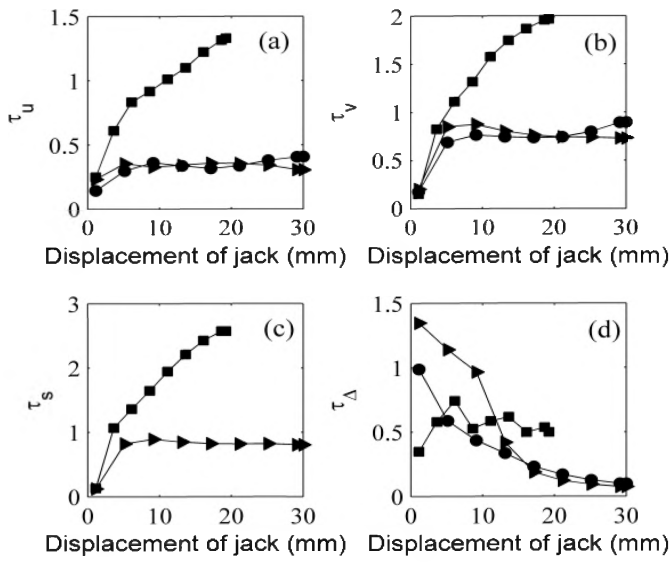

$=$ Position $1 \longrightarrow$ Position $2 \longrightarrow$ Position 3

Figure 6. Transfer ratios of the (a) maximal horizontal displacement, (b) maximal vertical displacement, (c) average slope, and (d) maximal deflexion.

greenfield have similar behaviour, $\tau=0$ means the deformation of the structure is negligible compared to that of the greenfield. Different transfer ratios can be introduced such as transfer ratio of the horizontal displacement $\left(\tau_{\mathrm{u}}\right)$ and the vertical displacement $\left(\tau_{\mathrm{v}}\right)$, of slope $\left(\tau_{s}\right)$, and of deflexion $\left(\tau_{\Delta}\right)$. The values of $\tau$ are determined at the same position in $x-y$ plane for both cases of the Greenfield and that of the presence of the structure. Each parameter provides different characters of the soil-structure interaction phenomena.

The first character of the soil-structure interaction is the transmission of the maximal horizontal displacement, represented by the parameter $\tau_{\mathrm{u}}$. The evolution of this transfer ratio appears on Figure 6a: the position $\mathrm{P}_{1}$ theoretically should correspond to zero horizontal displacement transmission, i.e. $\tau_{u}=0$. However, the observed average value $\tau_{u}=0.35$ is explained by the dissymmetrical movements of the soil mentioned before. On the opposite, $\mathrm{P}_{2}$ must theoretically have a positive value for $\tau_{u}$ due to the identical movement between structure and soil. As a result, the tests demonstrate $\tau_{u}>0$, even though the average value is similar to that of $P_{1}$. For position $P_{3}, \tau_{u}$ increases constantly with a final value $\tau_{u}=1.33$. The significant value can be explained by the fact that the structure model occupies $1 / 2$ of the subsidence area.

Concerning the transmission of the maximal vertical displacement $\tau_{\mathrm{v}}$ as shown in Figure $6 \mathrm{~b}$, the values of $\tau_{v}$ are more significant than that of $\tau_{u}$. Particular attention is paid to the trend of $\tau_{u}$ and $\tau_{v}$ for $P_{1}$ and $\mathrm{P}_{2}$, in which the transfer ratios are horizontally stationary, whereas $\mathrm{P}_{3}$ can be divided in an initial part (threshold of $10-15 \mathrm{~mm}$ for the jack displacement) and a subsequent non-linear part. This means that $\mathrm{P}_{3}$ has more potential damage which is proportional with the increasing ratios.

The transfer ratio of the average slope $\tau_{\mathrm{s}}$ is presented in Figure 6c. The average slope is the gradient of the 


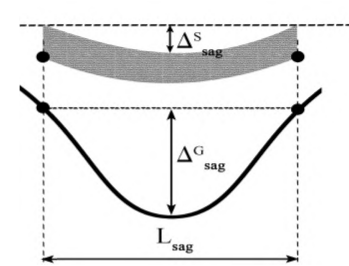

(a)

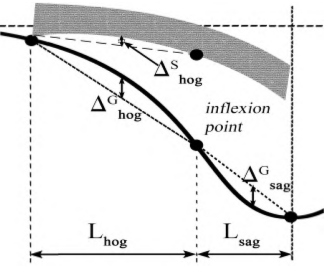

(b)
Figure 7. Definition of deflexion ratios (after Potts and Addenbrooke, 1997). a) Position $P_{1}$. b) Positions $P_{2}$ and $P_{3}$.

vertical displacements which are calculated from the two extremities of the foundation. The values of $\tau_{s}$ in $\mathrm{P}_{1}$ cannot be computed because the average slopes in the greenfield case are very close to zero and the determination of $\tau_{\mathrm{s}}$ is therefore no longer accurate or has no sense. The trend observed for $\mathrm{P}_{2}$, and $\mathrm{P}_{3}$ are similar to those found in Figures $6 \mathrm{a}, \mathrm{b}$.

The most interesting parameter is the transfer ratios of deflexion $\tau_{\Delta}$. The definition of these ratios has been suggested by Potts and Addenbrooke, 1997 and its adaptation to this study is illustrated in Figure 7. The position $\mathrm{P}_{1}$ corresponds to a pure sagging situation (Fig. 7a), whereas for $\mathrm{P}_{2}$ and $\mathrm{P}_{3}$ the structure can be divided in both hogging and sagging parts (Fig. $7 \mathrm{~b}$ ). Due to the significant length of the structure compared to the settlement trough width and the area of the structure occupies about $70 \%$ of the subsidence surface, the structure occupies both hogging and sagging parts of the ground. Consequently, we consider only the hogging part for the evaluation of deflexion ratios.

The evolution of $\tau_{\Delta}$ is represented in Figure 6d. The values obtained for $\mathrm{P}_{1}$ and $\mathrm{P}_{2}$ degrade quickly, while for $\mathrm{P}_{3} \tau_{\Delta}$ is almost stationary. In the Greenfield case, the deflexions for $\mathrm{P}_{1}$ are more important than for $P_{2}$ and $P_{3}$. Theoretically, the value of $\tau_{\Delta}$ for $P_{2}$ is around 1 . However, the values degrade quickly as well as for $\mathrm{P}_{1}$ because of the position of the inflexion point is considered as constant. This aspect adds an incertitude on the calculated deflexion ratio.

A particular attention is paid to the trend of the transfer ratios for the displacements and the slope in the case of position $\mathrm{P}_{3}$ (Figs. 6a-c). All the values are larger than 1 when the jack displacement exceeds $10 \mathrm{~mm}$. This can be explained by the fact that the vertical displacement of the foundation in the $\mathrm{x}$ direction is associated with that of the y direction. In fact, this position is equivalent to the association of two positions: $P_{2}$ in $x$ direction (monitored direction) and $P_{1}$ in $y$ direction. The important homogenous settlement of the foundation in y direction leads the foundation in $\mathrm{x}$ direction to exhibit more displacements than in the Greenfield case. Accordingly, the transfer of the slope presents a similar trend.

\subsection{Damage assessment}

This section compares different methods for assessing damage in the structure using the criteria on the limit slope (see Loganatban, 2011), the limit tensile
Table 1. Damage classification (Boscardin and Cording, 1989 and see Loganatban, 2011).

\begin{tabular}{llll}
\hline ID & Damage class & $\begin{array}{l}\text { Maximum } \\
\text { slope }\end{array}$ & $\begin{array}{l}\text { Limit tensile } \\
\text { strain (\%) }\end{array}$ \\
\hline $\mathrm{N}_{1}$ & Negligible & $0-1 / 500$ & $0-0.05$ \\
$\mathrm{~N}_{2}$ & Very slight to slight & $1 / 500-1 / 200$ & $0.05-0.15$ \\
$\mathrm{~N}_{3}$ & Moderate & $1 / 200-1 / 50$ & $0.15-0.3$ \\
$\mathrm{~N}_{4}$ & Severe to very severe & $>1 / 50$ & $>0.3$ \\
\hline
\end{tabular}
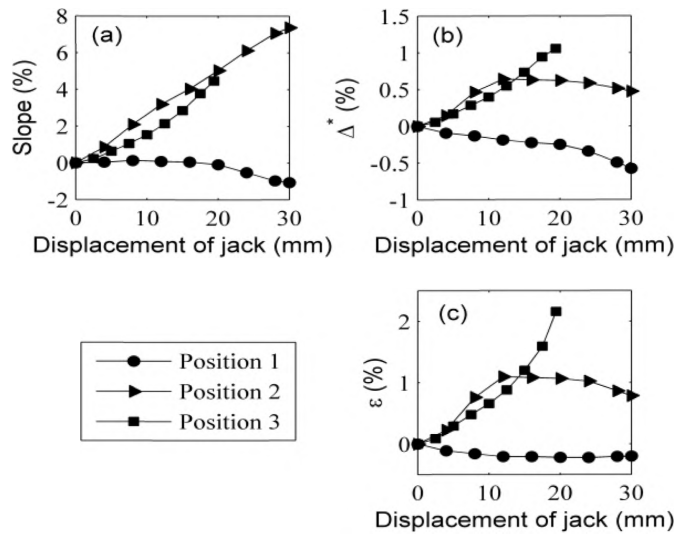

Figure 8. Damage parameters related to (a) the average slope of the foundation, (b) the relative maximal deflexion of the foundation, and (c) the maximal horizontal deformation of the masonry wall.

strain (Boscardin and Cording, 1989), the method of Burland, 1997. Table 1 summarizes the different classifications.

Application of risk assessment methods needs determining the following parameters: average slope of the foundation, relative value of the maximal deflexion of the foundation and maximal horizontal deformation of the structure. The maximal horizontal deformation is calculated based on the maximal extension length of the structure. Specifically, the maximal deflexion at the present time is calculated over the full length of the structure.

The damage level can be directly evaluated using the values of the average slope (Fig. 8a) or the maximal deformation (Fig. 8c). Another way is to use the method of Burland, 1997, in which the maximal deflexion (Fig. 8b) is combined with the maximal deformation. Herein, we summarize the main results as shown in Table 2.

Regarding the position of cracks reported in Figure 9 (for the same value of the jack displacement i.e. $30 \mathrm{~mm}$ ), the position $P_{1}$ should correspond to the moderate damage category, $\mathrm{P}_{2}$ should be in the severe to very severe damage category, and $\mathrm{P}_{3}$ is in the collapse. Discrepancies between the 3 methods are highlighted in the Table 3 and indicate that the method of Burland is not applicable for the present model. 
Table 2. Damage evaluations.

\begin{tabular}{clll}
\hline $\begin{array}{l}\text { Jack } \\
\text { displacement }\end{array}$ & Slope & Deformation & $\begin{array}{l}\text { Burland } \\
\text { (deformation- } \\
\text { deflexion) }\end{array}$ \\
\hline $10 \mathrm{~mm}$ & & & \\
$\mathrm{P}_{1}$ & $\mathrm{~N} 1$ & $\mathrm{~N} 3$ & $\mathrm{~N} 3$ \\
$\mathrm{P}_{2}$ & $\mathrm{~N} 4$ & $\mathrm{~N} 4$ & $\mathrm{~N} 4$ \\
$\mathrm{P}_{3}$ & $\mathrm{~N} 3$ & $\mathrm{~N} 4$ & $\mathrm{~N} 4$ \\
$20 \mathrm{~mm}$ & & & \\
$\mathrm{P}_{1}$ & $\mathrm{~N} 3$ & $\mathrm{~N} 3$ & $\mathrm{~N} 4$ \\
$\mathrm{P}_{2}$ & $\mathrm{~N} 4$ & $\mathrm{~N} 4$ & $\mathrm{~N} 4$ \\
$\mathrm{P}_{3}$ & $\mathrm{~N} 4$ & $\mathrm{~N} 4$ & $\mathrm{~N} 4$ \\
$30 \mathrm{~mm}$ & & & \\
$\mathrm{P}_{1}$ & $\mathrm{~N} 3$ & $\mathrm{~N} 3$ & $\mathrm{~N} 4$ \\
$\mathrm{P}_{2}$ & $\mathrm{~N} 4$ & $\mathrm{~N} 4$ & $\mathrm{~N} 4$ \\
$\mathrm{P}_{3}$ & $\mathrm{Collapse}$ & $\mathrm{Collapse}$ & $\mathrm{Collapse}$ \\
\hline
\end{tabular}
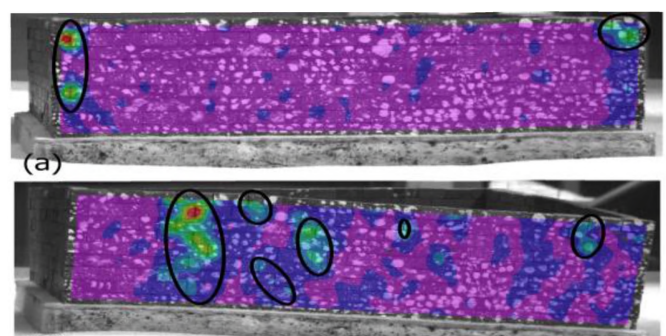

(b)

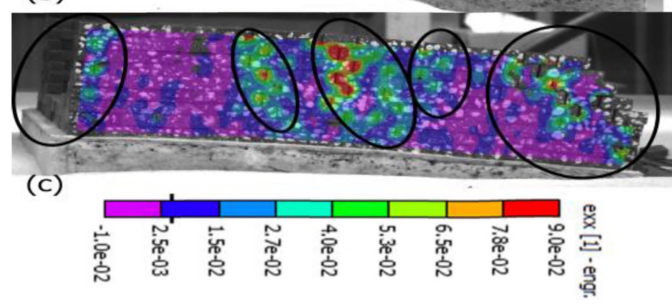

Figure 9. Final stages of the observed wall of structure in (a) sagging zone-position $\mathrm{P}_{1}$, (b) hogging zone-position $\mathrm{P}_{2}$, and (c) mixed zone-position $P_{3}$ (jack displacement $=30 \mathrm{~mm}$ ).

\section{CONCLUSION}

The presented work discussed the soil-structure interaction and the assessment of damage in a structure using physical modelling. Different positions of the structure have been investigated in order to take into account the different applied parameters of the subsidence: slope, curvature, etc.
The study showed that there is a significant change of behaviour of the soil-structure interaction when the trough reaches its critical width. The observed behaviour of the structure can be divided into two distinct parts: an initial linear part and the subsequent non-linear part.

The research may be improved with more realistic models of the foundation (instead of a raft) or masonry structure with mortar.

\section{REFERENCES}

Al Heib, M. 2003. Paramètres d'affaissement pour la hiérachisation des zones à risques dans le bassin ferrière lorrain. Après-mines 2003.

Al Heib, M., Emeriault, F., Caudron, M., Nghiem, L. \& HOR, B. 2013. Large-scale soil-structure physical model (1g)assessment of structure damages. International Journal of Physical Modelling in Geotechnics, 13, 138-152.

Boscardin, M. \& Cording, E. 1989. Building Response to Excavation-Induced Settlement. Journal of Geotechnical Engineering, 115, 1-21.

Burland, J. 1997. The assessment of the risk of damage to buildings due to tunnelling and excavations.

Caudron, M. 2007. Etude expérimentale et numérique de l'interaction sol-structure lors de l'occurence d'un fontis. INSA de Lyon.

Deck, O., Al Heib, M. \& Homand, F. 2003. Taking the soilstructure interaction into account in assessing the loading of a structure in a mining subsidence area. Engineering Structures, 25, 435-448.

Giardina, G., Marini, A., Hendriks, M. A. N., Rots, J. G., Rizzardini, F. \& Giuriani, E. 2012. Experimental analysis of a masonry façade subject to tunnelling-induced settlement. Engineering Structures, 45, 421-434.

Hor, B. 2012. Evaluation et réduction des conséquences des mouvements de terrains sur le bâti: approches expérimentale et numérique. Thesis, Institut National des Sciences Appliquées de Lyon.

Laefer, D. F., Hong, L. T., Erkal, A., Long, J. H. \& Cording, E. J. 2011. Manufacturing, assembly, and testing of scaled, historic masonry for one-gravity, pseudo-static, soil-structure experiments. Construction and Building Materials, 25, 4362-4373.

Loganatban, N. (ed.) 2011. An innovative method for assessing tunnelling-induced risks to adjacent structures: Parsons Brinckerhoff Inc.

Potts, D. M. \& Addenbrooke, T. I. 1997. A structure's influence on tunnelling-induced ground movements. Proceedings of the Institution of Civil EngineersGeotechnical Engineering, 125, 109-125. 